\title{
determinación rápida del ión cloruro en yesos, arcillas y cementos
}

JOSE $M$ a FERNANDEZ PARIS

Perlta Industrlal Quimico del Departamento

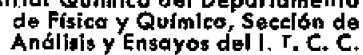

\section{INTRODUCCION}

En los arcillas y cementos no suele llevarse a cabo la determinación del ión cloruro, aunque puede ocurrir que en determinodos momentos revista importancia. Su determinación en los yesos la aconsejan las normas (NELC 3.03 a). En las arcillas entra como constituyente de la sodalita, es decir, en aquellas arcillas que tienen algún feldespato sustituído. [1]. Los cementos lo contendrón, si bien en pequeñísimas proporciones, debido al yeso que se le adiciona al clínker con el fin de regular su fraguado.

Generalmente, cuando es preciso hacer esta determinación, se siguen procedimientos clásicos, tales como el método de Mohr y Volhard, ambos volumétricos, y el procedimiento gravimétrico. En todos ellos se utiliza una disolución de nitrato de plata, que frente al ión cloruro producirá cloruro de plata, prácticamente insoluble y muy poco ionizado, siempre que se opere en medio débilmente nítrico. En las determinaciones volumétricas el líquido resultante de la reacción se presenta turbio, debido a la precipitación del cloruro de plata blanco; este enturbiamiento, la moyor parte de las veces, es suficientemente pronunciado para enmascarar el final de la reacción $y$, además, no se conoce hasta el presente una sustancia capaz de producir un punto de viraje claro y terminante. Aunque pueden utilizarse métodos potenciométricos y conductimétricos que actúan independientes de la furbidez, corrientemente se usan disoluciones de cromato potásico, unas veces como indicador interno (cambio gradual de intensidad), otras como indicador externo, lo que produce gran pérdida de tiempo y seguridad. El procedimiento gravimétrico tiene el inconveniente de ser largo y requerir grandes cuidados.

Se expone un método, basado en estudios llevados a cabo por Clarke (2), que han permitido valorar el ión cloruro que se encuentra presente en las aguas naturales (3) en el que se lleva a cabo la dosificación del ión cloruro en los yesos, cementos y arcillas, que, al mantener la muestra clara durante toda la determinación, permite dosificar cantidades de hasta $700 \mathrm{mg}$ de jón cloro sin necesidad de diluir. El punto de viraje es neto, ya que se pasa del amarillo al violeta $\sin$ tonalidades intermedias, por lo que el punto final de la valoración es terminante. Incluso se puede aplicar a disoluciones coloreadas con sólo añadirles una pequeñísima capa de éter etílico, por observarse en ella muy bien el cambio de coloraçión.

\section{Fundamento del método}

Se basa en la reacción del ión cloro y el ión mercúrico (aportado por una disolución de nitrato mercúrico), en la que se forma cloruro mercúrico, de disolución muy limitada, cuando se opera en un medio débilmente nítrico (3).

Si se añade una disolución de nitrato mercúrico a otra de ión cloro, ambos iones se combinan con formación de cloruro mercúrico, el cual se disuelve. Ahora bien, cuando se combina todo el ión cloruro pre- 
sente, se puede patentizar el ión mercúrico que proviene del nitrato mercúrico en exceso.

Para lograr singularizarlo, Clarke utiliza la difenilcarbazona como indicador, siempre que se opere con disoluciones débilmente nítricas. La difenilcarbazona por ser un indicador muy sensible del ión mercúrico permite dosificar el ión cloruro mediante una disolución valorada de nitrato mercúrico $e$, incluso, no interfieren los iones de metales pesados.

La valoración se lleva a cabo dentro de ciertos límites del $\mathrm{pH}$, eliminando sin excuso la alcalinidad de la solución mediante adición de ácido nítrico y como indicador el azul de bromofenol, el cual adquiere el tono azul para el campo alcalino y amarillo para los ácidos, pasando por una tonalidad rosada en la zona neutra. Su tonalidad amarilla para un $\mathrm{pH} 3,5$ no enmascara el viraje violeta del complejo mercúrico-difenilcarbazona. El pH óptimo de la disolución a valorar se encuentra entre 3,2 y 3,1 [3].

\section{Reactivos a emplear}

Indicador de Azul de Bromofenol. - 1 gr de azul de bromofenol se disuelve en $100 \mathrm{ml}$ de alcohol etílico.

Indicador de Difenilcarbazona. - $1 \mathrm{gr}$ de difenilcarbazona se disuelve en $100 \mathrm{ml}$ de alcohol etílico.

Acido Nítrico, 0,1 N.-Se diluyen $6,4 \mathrm{ml}$ de ácido nítrico concentrado hasta 1.000 $\mathrm{ml}$ con agua destilada.

Hidróxido Sódiço 0,1 N.-- Se disuelven 5 gr de hidróxido sódico en forma de lentejas en $1.000 \mathrm{ml}$ de agua destilada. El frasco se cierra con tapón de goma virgen o, mejor, se conserva en un frasco de plástico.

Disolución valorada de nitrato de mercurio.-Se disuelven, exactamente, 3,084 gr de óxido de mercurio rojo en $3,6 \mathrm{ml}$ de acido nítrico concentrado $y$, aproximadamente, $20 \mathrm{ml}$ de agua destilada y se calienta ligeramente. Una vez fría la disolución se completa hasta $1.000 \mathrm{ml}$ con agua destilada y se filtra si fuera preciso. Un $\mathrm{ml}$ de esta disoluçión equivale aproximadamente a un mg de ión cloro, si bien es preciso comprobarla con referencia a una disolución tipo de cloruro potásico, que se obtiene disol- viendo $0,2108 \mathrm{gr}$ de cloruro potásico en 100 $\mathrm{ml}$ de agua destilada perfectamente medidos en un matraz aforado de garantía; con lo. cual, cada ml de la solución patrón contiene un mg de ión cloro.

Valoración del nitrato mercúrico.-Se introducen en un vaso de $50 \mathrm{ml}$ de forma alta $20 \mathrm{ml}$, exactomente medidos, de la disolución patrón de cloruro potásico; se añaden $80 \mathrm{ml}$ de agua destilada y $2 \mathrm{ml}$ de la disolución de azul de bromofenol; se agita y se añade ácido nítrico $0,1 \mathrm{~N}$, gota a gota, hasta que el indicador tome una tonalidad amarilla franca, y se añade $1 \mathrm{ml}$ de ácido nítrico $0,1 \mathrm{~N}$ en exceso. Entonces se adicionan $2 \mathrm{ml}$ de la disolución indicadora de difenilcarbazona y se valora con la disolución de niłrato mercúrico, introducido en una bureta, lentamente y agitando hasta que el líquido a dosificar vira a un tono francamente violeta

Entonces se tiene que si $\mathrm{n}=\mathrm{ml}$ de nitrato mercúrico gastados, un $\mathrm{ml}$ de nitrato mercúrico $=\frac{0,020}{\mathrm{n}} \mathrm{gr}$ de $\mathrm{Cl}^{-}$, puesto que en los $20 \mathrm{ml}$ de la disolución de cloruro potásico hay exactamente $0,020 \mathrm{gr}$ de ión cloruro.

\section{Modo de operar}

a)-ARCILLAS. - Se toma un gramo de la muestra, previamente molida hasta quedar reducida a un polvo impalpable, mediante un mortero de ágata - no utilizando nunca tamices ya que podrían quedarse particulas específicos retenidas entre sus mallas- y cuidadosamente desecada en estufa a $110^{\circ} \mathrm{C}$ hasta un peso constante. Este gr se introduce en un crisol de platino con $7 \mathrm{gr}$ de carbonato sodo-potásico; se mezcla el contenido del crisol y se remueve con una varilla fina de vidrio. Esto se debe ejecutar con mucho cuidado, ya que la sustancia que queda entre la pared y el fondo del crisol debe mezclarse bien, ya que, de lo contrario, se forma en la pared una masa no atacada del todo, la cual luego se disuelve mal en los ácidos. Una vez bien removido, se cubre $y$ se calienta durante quince minutos sobre un mechero Bunsem, con poca llama, y después, fuertemente durante cinco minutos sobre un Teclú, puesto 
que un calentamiento excesivo al principio podría dar lugar a un fuerte desprendimiento de $\mathrm{CO}_{y}$ con salpicaduras. Cuando el contenido del erisol no se haya fundido completamente, y si únicamente concrecionodo, se llena otra vez con carbonato sodo-potásico; se cubre de nuevo y se calienta con cuidado cinco minutos sobre ltama mediana del Teclú, y luego diez minutos fuertemente sobre Teclú. Se nota que ha terminado la fusión por no existir desprendimiento de $\mathrm{CO}_{2}$. Para observar esto se levanta un poco la fapa de platino con las pinzas, mientras el fondo se sigue calentando para comprobar mejor la posible existencia de burbujas que ascienden desde el fondo. Se evita la pérdida de sustancia por salpicadu. ras, sosteniendo la tapa del crisol a poca altura.

Concluída la fusión se enfría el crisol, se coloca primero la tapa de platino en una cápsula de porcelana de unos $10 \mathrm{~cm}$ de diámetro; se agrega un poco de agua y después unos $\mathrm{ml}$ de ácido nítrico concentrado. Tan pronto como se haya disuelto la sustancia adherida a la tapadera se saca ésta con una varilla de vidrio; se lava con agua y se deja aparte. Entonces el crisol con la masa fundida se pone en la cápsula y se cubre rápidamente con un vidrio de reloi. En cuanto el desprendimiento de $\mathrm{CO}_{2}$ disminuye, se añade, poco a poco, ácido nítrico concentrado. Cuando la reacción haya concluido, es decir, cuando se ha separado del crisol la masa fundida, se levanta cuidadosamente el vidrio de reloi; se lava su interior y se deja aparte. El crisol se levanta sobre el liquido con una varilla de vidrio; se lava bien por dentro y por fuera y se deja aparte. La cápsula se pone a ebullición cinco minutas, se aparta del mechero y se deja enfriar. Una vez fría se filtra por un papel banda blanea de Schleicher \& Schull a un vaso de $250 \mathrm{ml}$ de forma alta, se lava 7 y 8 veces con agua muy caliente ayudándose de un frasco lavador.

Al contenido del vaso (unos $100 \mathrm{ml}$ ) se le añade $2 \mathrm{ml}$ de la disolución de azul de bromofenol y, entonces, puede suceder:

a) Que el líquido tome una coloración azul (disolución alcalina); entonces se añade disolución de ácido nítrico 0,1 N, gota a gota, hasta que el contenido del vaso tome una coloración francamente amarilla $y$ se le añade $1 \mathrm{ml}$ de ácido nítrico en exceso; b) Que el líquido tome una coloración amarilla o rosa (disolución ácida); en este. caso se añade disolución de hidróxido sódico $0.1 \mathrm{~N}$, gota a gota, hasta coloración azul. Una vez que ha adquirido esta tonalidad se agrega ácido nítrico $0,1 \mathrm{~N}$, gota a gota, hasta coloración francamente amarilla del contenido del vaso, y se añade un $\mathrm{ml}$ de ácido nítrico $0,1 \mathrm{~N}$ en exceso.

Una vez que el $\mathrm{pH}$ conseguido es 3,1 ó 3,2, por los procedimientos anteriormente descritos, el problema está en condiciones de valorarse.

Al contenido del vaso se le agregan 2 $\mathrm{ml}$ de indicador alcohólico de difenilcarbazona, se agita bien; y mediante una bureta se va añadiendo, gota a gota, disolución valorada de nitrato mercúrico, hasta que el líquido vira a un tono marcadamente violeto. Se anota el número de $\mathrm{ml}$ gastados de nitrato mercúrico.

b) - YESO. - De la muestra para analizar se toma una porción de unos $50 \mathrm{gr}$, que se deseca en la estufa a unos $45^{\circ} \mathrm{C}$ durante dos horas, extendida en capas de pequeño espesor. Se deja enfriar en el desecador; se pulveriza la muestra lo más rápidamente posible, con el fin de evitar la acción de la humedad, hasta que pase por completo por el tamiz de 576 mallas por centímetro cuadrado, $y$ después de homogeneizarla se guarda en un desecador hasta el momento de su análisis.

Se pesa $1 \mathrm{gr}$ de muestra, tratada como antes hemos dicho, se disuelve en unos 100 $\mathrm{ml}$ de agua caliente; se tiene a ebullición durante 15 minutos; se deja enfriar; se filtra por un filtro de papel banda blanca de Schleicher \& Schull a un vaso de $250 \mathrm{ml}$ de forma alta y se lava 7 u 8 veces con agua muy caliente (4).

Al contenido del vaso (unos $150 \mathrm{ml}$ ) se le añaden $2 \mathrm{ml}$ de la disolución de azul de bromofenol y, entonces, el líquido tomará una coloración azul (disolución alcalina) o rosada (disolución neutra). Se añade ácido nítrico $0,1 \mathrm{~N}$, gota a gota, hasta que el contenido del vaso tome una coloración francamente amarilla, y se le añade $1 \mathrm{ml}$ de ácido nítrico 0,1 $\mathrm{N}$ en exceso.

Al contenido del vaso se le agrega $2 \mathrm{ml}$ de indicador alcoholico de difenilcarbazona, se agita bien; y mediante una bureta, 
se va añadiendo, gota a gota, disolución valorada de nitrato mercúrico, hasta que el líquido vira a un tono marcadamente violeta. Se anota el número de $\mathrm{ml}$ gastados de nitrato mercúrico.

c)-CEMENTO.-De la muestra enviada al laboratorio para su análisis se separa una porción de unos $10 \mathrm{gr}$, que se desecarán en una estufa a $110^{\circ} \mathrm{C}$ hasta peso constante.

Se pesa $1 \mathrm{gr}$ de la muestra tratada como anteriormente se dice; se disuelve en unos $100 \mathrm{ml}$ de agua caliente y $5 \mathrm{ml}$ de ácido nítrico concentrado y se mantiene a ebullición durante 15 minutos; se deja enfriar, se filtra por un filtro de papel banda blanca de Schleicher \& Schull a un vaso de $250 \mathrm{ml}$ de forma alta y se lava 7 y 8 veces con agua muy caliente.

Al contenido del vaso se le añaden $2 \mathrm{ml}$ de la disolución de azul de bromofenol y, entonces, el líquido tomará una coloración azul (disolución alcalina). Se añade ácido nítrico $0,1 \mathrm{~N}$, gota a gota, hasta que el contenido del vaso tome una coloración francamente amarilla, y se le añade $1 \mathrm{ml}$ de ácido nítrico $0,1 \mathrm{~N}$ en exceso.

Al contenido del vaso se le agregan 2 $\mathrm{m} /$ de indicador alcohólico de difenilcarba. zona, se agita bien; y mediante una bureta, se va añadiendo, gota a gota, disolución valorada de nitrato mercúrico, hasta que el liquido vira a un tono marcadamente violeta. Se anota el número de $\mathrm{ml}$ gastados de nitrato mercúrico. nomingn:

CÁLCULO DEL RESULTADO.--Si se de-

$\mathrm{N}=\mathrm{ml}$ de nitrato mercúrico gastados;

$\mathrm{m}=$ equivalencia, en $\mathrm{gr}$, de cada $\mathrm{ml}$ de nitrato mercúrico;

$\mathrm{P}=$ peso, en gr, de la muestra; N. $\frac{m \cdot 100}{\mathrm{p}}=\%$ de $\mathrm{Cl}^{-}$.

\section{Observaciones y fablas}

Las determinaciones llevadas a cabo por la Sección de Análisis del Departamento de Física y Química del Instituto Técnico de la Construcción y del Cemento ponen de ma- nifiesto el paralelismo del método expuesto con el procedimiento gravimétrico. Se ha tomado este último como referencia por su mayor garantía en cuanto a exactitud de los resultados.

$\begin{array}{cccc} & & \begin{array}{c}\text { Con } \\ \text { Nitrato Mercurlco }\end{array} & \begin{array}{c}\text { Por } \\ \text { Gravimetria }\end{array} \\ \text { Arcilla } & 1 & 0,20 \% & 0,19 \% \\ \Rightarrow & 2 & 0,33 & 0,34 \\ \Rightarrow & 3 & 0,76 & 0,75 \\ \text { Yeso } & 1 & 0,30 & 0,27 \\ \Rightarrow & 2 & 0,37 & 0,33 \\ \Rightarrow & 3 & 0,50 & 0,51 \\ \text { Cemento } & 1 & 1,12 & 1,10 \\ \Rightarrow & 2 & 1,10 & 1,08 \\ \Rightarrow & 3 & 0,96 & 0,95\end{array}$

\section{BIBLIOGRAFIA}

1. Dr. J. JAKOB: Guía para el Análisis Químico de Rocas, pág. 83.

2. F. E. CLARKE: Anal. Chem. 22, 553-5 (1950).

3. L. F. SAINZ ASTORGA: Rev. Técnica Industrial, pág. 196 (1958).

4. Dr. J. CALLEJA: Curso para Formación de Auxiliares de Laboratorio en la Industria del Cemento. Tomo II, póg. 137 (1954).

\section{Resumen}

Se describe un método para la determinación del ión cloruro en las arcillas, yesos y cementos, rápido y con un punto de viraje terminante que se corresponde perfectamente con la ecuación estequiométrica que tiene lugar durante la valoración. La individualización del ion mercúrico en exceso mediante la difenilcarbazona ha permitido determinar el ión cloruro mediante una disolución valorada de nitrato mercúrico. El autor ha introducido algunas modificaciones, que cree hacer más fácil la 
determinación, tales como utilizar los indicadores separadamente, la expresión del cálculo de los resultados, forma de determinar y valorar la disolución de nitrato mercúrico. El tiempo que dura la determinación, incluído el ataque de la muestra, es de euarenta $y$ cinco minutos para las arcillas y de veinticinco para los yesos y cementos. Su principal ventaja reside en que la muestra es completamente nítida $y$ transparente durante todo el tiempo que dura la dosificación. Se expone una tabla en la que se pone de manifiesto el paralelismo del método de nitrato mercúrico expuesto con el procedimiento gravimétrico tradicional con nitrato de plata (se ha tomado éste como referencia por su mayor garantía en cuanto a exactitud de los resultados que cualquiera de los procedimientos volumétricos corrientes).

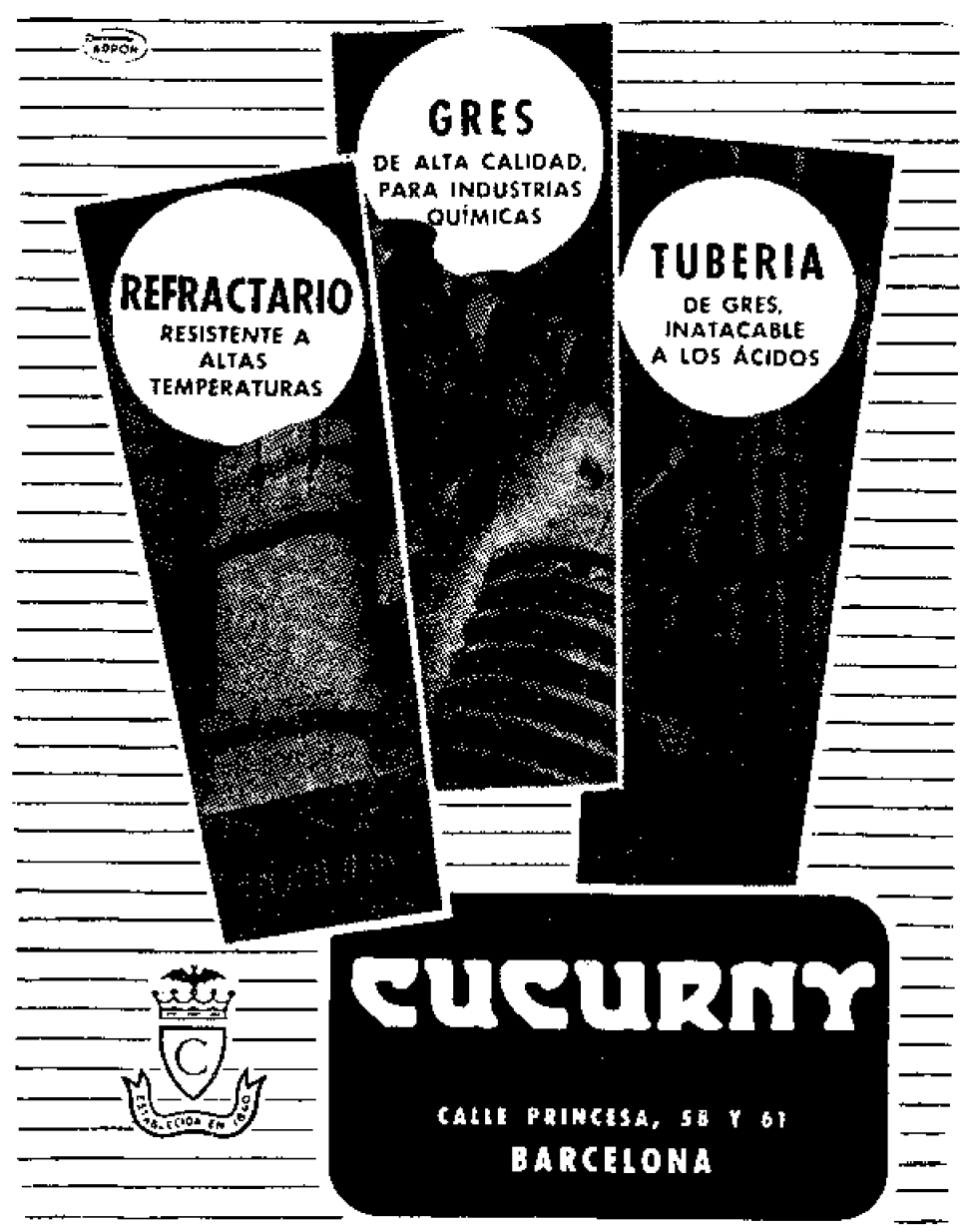

